\title{
Replacing $\mathrm{Mn}^{2+}$ with $\mathrm{Co}^{2+}$ in Human Arginase I
}

\section{Enhances Cytotoxicity Towards L-Arginine Auxotrophic}

\section{Cancer Cell Lines}

Everett M. Stone ${ }^{a}$, Evan S. Glazer ${ }^{b}$, Lynne Chantranupong $^{a}$, Paul Cherukuri $^{b}$, Robert M. Breece , $^{c}$ David L. Tierney, Steven A. Curley ${ }^{b}$, Brent L. Iverson ${ }^{d e}$ and George Georgiou ${ }^{a d^{*}}$

${ }^{\mathrm{a}}$ Departments of Chemical Engineering, Biomedical Engineering, Molecular Genetics and Microbiology and ${ }^{\mathrm{d}}$ Institute for Cell and Institute for Molecular and Cell Biology, ${ }^{\mathrm{e}}$ Department of Chemistry \& Biochemistry, University of Texas, Austin, TX 78712; ${ }^{b}$ Department of Surgical Oncology, University of Texas, M. D. Anderson Cancer Center, Houston, TX 77030, and ${ }^{\mathrm{c}}$ Dept. of Chemistry and Biochemistry, Miami University, Oxford, OH 45056.

*E-mailgg@che.utexas.edu

*Address correspondence to: George Georgiou, Ph.D., 1 University Station, C0800 Austin, Texas 78712-1084, Phone: (512) 471-6975, Fax: (512) 471-7963,_E-mail gg@ che.utexas.edu

SUPPORTING INFORMATION 
Figure S1. Purification of hArgI: MW = Molecular Weight, $\mathrm{WC}=$ whole cell lysate, $\mathrm{SN}=$ soluble fraction, $\mathrm{FT}=$ flow though, and $\mathrm{El}=$ elution.

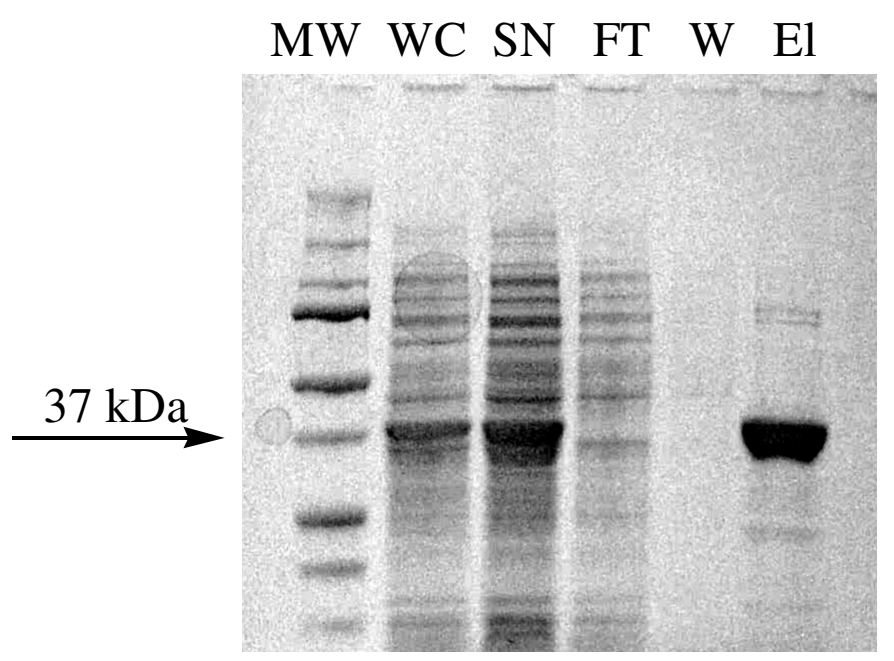


Figure S2. Best fits to Co-hArgI EXAFS. Fit numbers correspond to Table 1.
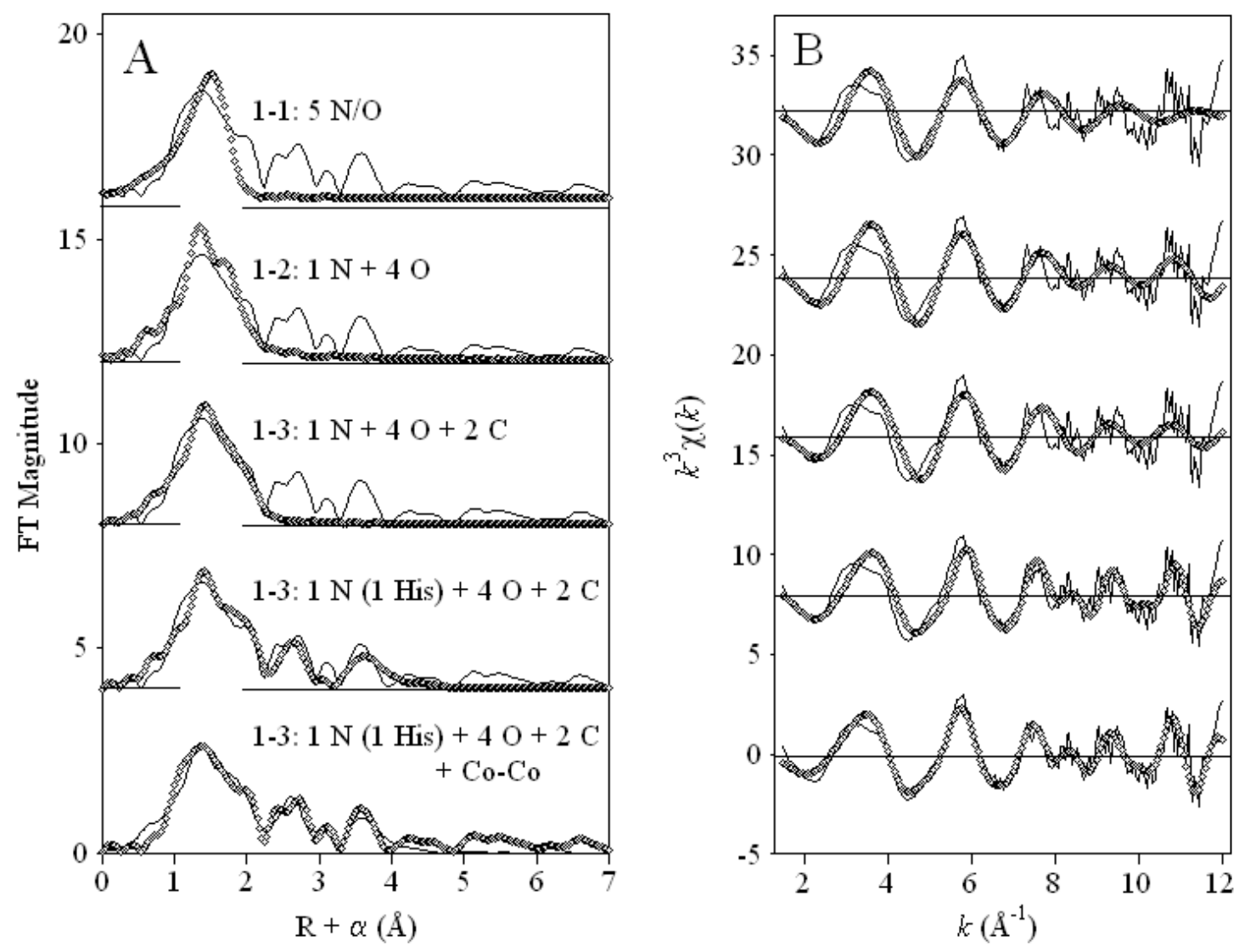
Table S1. Best fits to Co-hArgI EXAFS ${ }^{\mathrm{a}}$.

\begin{tabular}{|c|c|c|c|c|c|c|c|}
\hline Fit & Model & $M-N / O$ & $M-C$ & M-His ${ }^{\mathrm{b}}$ & $M-M$ & $\mathrm{R}_{\mathrm{f}}^{\mathrm{c}}$ & $\mathrm{R}_{\mathrm{u}}$ \\
\hline & $\mathrm{Co}_{2}-\mathrm{ArgI}$ & & & & & & \\
\hline $1-1$ & $5 \mathrm{~N} / \mathrm{O}$ & $2.10(11)$ & & & & 199 & 358 \\
\hline $1-2$ & $1 \mathrm{~N}+4 \Omega$ & {$[\mathrm{N}] 2.16(4.3)$} & & & & 66 & 272 \\
\hline & $11 N+40$ & [O] $1.96(8.4)$ & & & & 00 & 212 \\
\hline $1-3$ & $1 \mathrm{~N}+4 \mathrm{O}+2 \mathrm{C}$ & $\begin{array}{l}{[\mathrm{N}] 2.15(1.0)} \\
{[\mathrm{O}] 1.96(9.8)}\end{array}$ & $2.48(9.3)$ & & & 36 & 240 \\
\hline $1-4$ & $1 \mathrm{~N}(\mathrm{His})+4 \mathrm{O}+2 \mathrm{C}$ & $\begin{array}{l}{[\mathrm{N}] 2.15(1.4)} \\
{[\mathrm{O}] 1.96(10)}\end{array}$ & $2.47(5.2)$ & $\begin{array}{l}2.95(1.0) 3.28(10) \\
4.07(9.0) \\
4.32(5.1)\end{array}$ & & 119 & 171 \\
\hline $1-5$ & $\begin{array}{l}1 \mathrm{~N}(\mathrm{His})+4 \mathrm{O}+2 \mathrm{C} \\
\quad+\mathrm{Co}-\mathrm{Co}\end{array}$ & $\begin{array}{l}{[\mathrm{N}] 2.15(1.8)} \\
{[\mathrm{O}] 1.96(0.4)}\end{array}$ & $2.47(5.2)$ & $\begin{array}{l}2.95(1.3) 3.31(14) \\
4.06(13) \quad 4.32(4.8)\end{array}$ & $\begin{array}{l}3.52 \\
(15)\end{array}$ & 66 & 126 \\
\hline
\end{tabular}

${ }^{a}$ Distances $(\AA)$ and disorder parameters (in parentheses, $\sigma^{2}\left(10^{-3} \AA^{2}\right)$ ) shown derive from integer or half-integer coordination number fits to filtered EXAFS data $\left[k=1.5-12 \AA^{-1} ; R=0.7-2.3 \AA\right.$ (fits $1-1$ to 1-3 and 2-1 to 2-3) or $0.3-4.0 \AA$ (fits $1-4,1-5,2-4$ and $2-5$ )].

b Multiple scattering paths represent combined paths, as described previously (see Materials and Methods).

${ }^{\mathrm{c}}$ Goodness of fit ( $\mathrm{R}_{\mathrm{f}}$ for fits to filtered data) defined as $1000 * \frac{\left.\sum_{i=1}^{N}\left[\mathrm{ke}\left(\chi_{i_{\text {calc }}}\right)\right]+\left[\mathrm{m}\left(\chi_{i_{\text {calc }}}\right)\right]\right\}}{\left.\sum_{i=1}^{N}\left[\operatorname{ke}\left(\chi_{i_{b s s}}\right)\right]+\left[\mathrm{m}\left(\chi_{i_{\text {obs }}}\right)\right]\right\}}$, where $\mathrm{N}$ is the number of data points. 